\title{
Comparison of Active and Passive Damping of Plate Vibration by Piezoelectric Actuators — FEM Simulation
}

\author{
M.S. KozIeń* And B. Ko€towski \\ Institute of Applied Mechanics, Cracow University of Technology \\ al. Jana Pawła II 37, 31-864 Cracow, Poland
}

\begin{abstract}
Application of piezoelectric shunt elements, distributed in suitable configuration on the external surfaces of vibrating plate is one of the contemporary method of reduction of its vibroactivity. The two techniques are applied: passive one and active one. The aim of simulations was to compare the minimisation effect for the two attempts. The plate was excited by point harmonic force with constant amplitude. Vibrations for the first mode were considered.
\end{abstract}

PACS: 33.15.Mt, 34.50.Ez, 77.22.Gm

\section{Introduction}

Negative effects connected with vibroacoustic processes must be reduced for many engineering structures built of plates. Among many of methods, which can be applied, in recent years application, designing of the smart structures is very popular. The smart materials are such constructions as rods, plates and shells for which there exist two parts: classic structure and actuators and regulation systems which are its integral part. The most popular in applications, as actuators, are the piezoelectric elements. These elements are parts of the electro-mechanical control systems for reduction of vibrations. The two attempts are possible: active one and passive one. The first attempt needs the external source of energy and suitable control system. The second one is the analogy to the mechanical dampers and is built of the electrical RL circuit. It is dedicated for the chosen frequency. The general ideas of the methods are presented by Eliott and Nelson [1] and Moheimani with Fleming $[2,3]$. The paper presents results of analysis which are the next step of simulations discussed in the articles [4-10] and monographs $[11,12]$. The presented results were discussed during the conference [13-15]. The aim of the paper is comparison of the reduction effect obtained for these two realizations for the case of the harmonically excited fixed-free-free-free plate for the same configuration of the piezoelectric damping shunts.

\section{Analyzed system, FEM model}

The simulations were done for the fixed-free-free-free plate. The model is connected with a plate existing in

* corresponding author; e-mail: kozien@mech.pk.edu.pl laboratory stand. The squared plate with dimensions $100 \times 100 \times 2 \mathrm{~mm}^{3}$ was made of aluminum. The four pairs of squared piezoelectric elements with dimensions $20 \times 20 \times 1 \mathrm{~mm}^{3}$ were placed on both sides of plate. Configuration and numbers of piezoelectric shunts are shown in Fig. 1 and the material properties in Table I. Vibration of plate was excited by concentrated harmonically variable force with amplitude $0.1 \mathrm{~N}$, placed in the middle of the plate edge opposite to the fixed line.

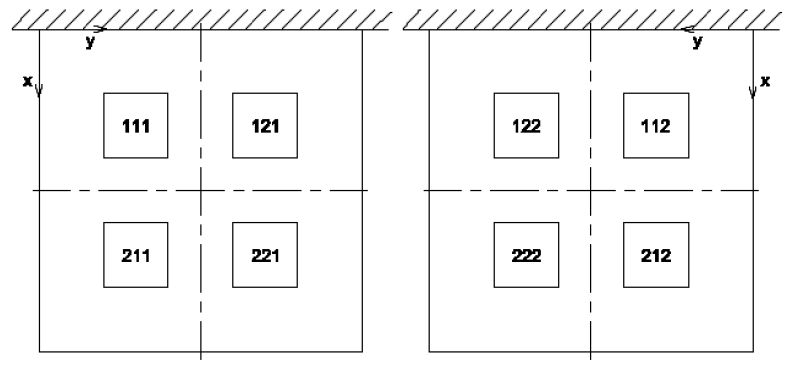

Fig. 1. Configuration of piezoelectric shunts and their numbers.

The finite element method (FEM) Ansys model was built of the following elements: solid45 for plate, solid5 for piezoelectric elements, combin 14 for boundary condition, circu45 for passive electric circuit. The theoretically fixed boundary condition was replaced by deformable ones after laboratory measurements. The spring constants for each plate node are equal to: transversal $5329 \times$ $10^{3} \mathrm{~N} / \mathrm{m}$, in-plane perpendicular to edge $2641 \times 10^{6} \mathrm{~N} / \mathrm{m}$, in-plane along the edge $8793 \times 10^{3} \mathrm{~N} / \mathrm{m}$ ) [13].

The analyses were reduced to the case of the vibrations for the first natural frequency. The final FEM model and the position of excitation force is shown in Fig. 2. 
Material properties.

TABLE I

\begin{tabular}{|c|c|c|c|}
\hline \multicolumn{2}{|c|}{ material } & $\mathrm{PZT} 4$ & aluminum \\
\hline \multicolumn{2}{|c|}{ Young modulus } & - & $72 \mathrm{GPa}$ \\
\hline \multicolumn{2}{|c|}{ Poisson ratio } & 0.29 & 0.33 \\
\hline \multicolumn{2}{|c|}{ Density } & $7500 \mathrm{~kg} / \mathrm{m}^{3}$ & $2704 \mathrm{~kg} / \mathrm{m}^{3}$ \\
\hline \multicolumn{2}{|c|}{ modal damping coefficient } & 0.0003 & 0.005 \\
\hline \multirow{3}{*}{$\begin{array}{l}\text { Charge } \\
\text { constants }\end{array}$} & $d_{31}$ & $60 \times 10^{-12} \mathrm{~m} / \mathrm{V}$ & \multirow[t]{3}{*}{-} \\
\hline & $d_{51}$ & $265 \times 10^{-12} \mathrm{~m} / \mathrm{V}$ & \\
\hline & $d_{33}$ & $200 \times 10^{-12} \mathrm{~m} / \mathrm{V}$ & \\
\hline \multirow{2}{*}{$\begin{array}{c}\text { Relative } \\
\text { permittivity }\end{array}$} & $\varepsilon_{11} / \varepsilon_{0}$ & 659.7 & \multirow[t]{2}{*}{-} \\
\hline & $\varepsilon_{33} / \varepsilon_{0}$ & 804.6 & \\
\hline
\end{tabular}

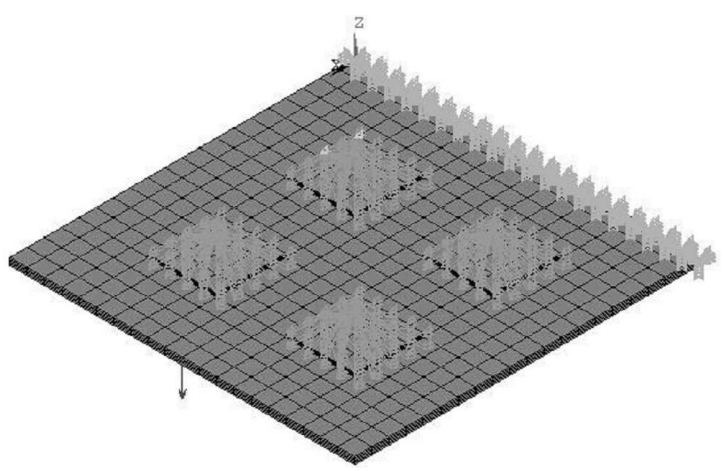

Fig. 2. FEM model and position of excitation force.

\section{Simulation of passive damping}

The passive damping means building of the suitable $R L C_{\mathrm{P}}$ circuit, designed for the chosen frequency, by which the energy of damping is transformed into heat in resistor. The natural frequency of the electrical circuit must be the same as the frequency of vibrating plate. Therefore the values of resistance and inductance must be calculated. The capacitance existing in the circuit is understood as the capacitance of piezoelectric elements. The model of electric circuit is shown in Fig. 3. The value of piezoelectric capacitance is estimated by the procedure given in [16]. After putting the voltage $V$ to external surface of piezoelectric element, charge $Q$ is obtained in it. Hence the capacitance of piezoelectric shunt element is given by formula (1). The obtained value in the model is equal to $C_{\mathrm{P}}=3.78 \times 10^{-9} \mathrm{~F}=3.78 \mathrm{nF}$.

$$
C_{\mathrm{P}}=\frac{Q}{V} \text {. }
$$

The values of coil inductance $L$ are obtained, having in mind the natural frequency of the circuit. For a given basic natural frequency of a plate the inductance is equal to $L=300.6 \mathrm{H}$.

$$
L=\frac{1}{\omega^{2} C_{\mathrm{P}}} .
$$

The value of resistance $R$, which gives the optimal damping in a system is estimated based on the Hagood and von Flotow procedure $[16,17]$ having in mind

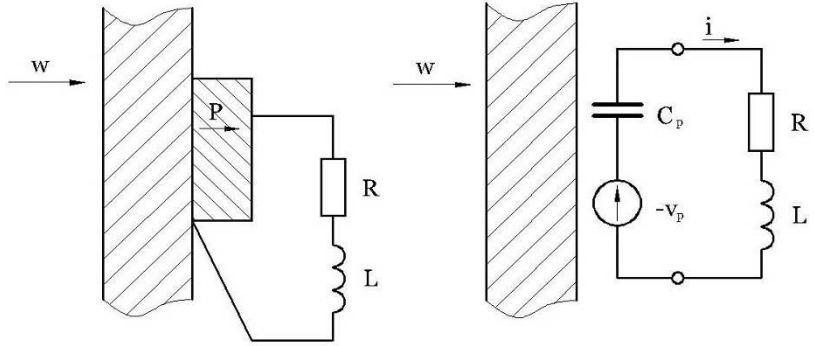

Fig. 3. $R L C_{\mathrm{P}}$ circuit (after [2]).

the coefficient of electro-mechanical coupling $K_{31}$ for the first natural frequency, where $\omega_{10}$ is the lowest natural frequency for open circuit, and $\omega_{1 \mathrm{~S}}$ for short circuit. For the presented analysis $\omega_{10}=939.1 \mathrm{rad} / \mathrm{s}$ and $\omega_{1 \mathrm{~S}}=938.0 \mathrm{rad} / \mathrm{s}$. Therefore the optimal value of resistance $R_{\mathrm{opt} 1}=18.5 \mathrm{k} \Omega\left(K_{31}=0.047\right)$.

$$
\begin{aligned}
& K_{31}=\sqrt{\frac{\omega_{1 \mathrm{O}}^{2}-\omega_{1 \mathrm{~S}}^{2}}{\omega_{1 \mathrm{~S}}^{2}}}, \\
& R_{\mathrm{opt} 1}=\frac{\sqrt{2} K_{31}}{\left(1+K_{31}^{2}\right) \omega_{1 \mathrm{O}} C_{\mathrm{P}}} .
\end{aligned}
$$

The passive damping was analyzed for the first natural frequency. Each of the pair of piezoelectric elements were actuators, the last pair was the detector of vibrations. The actuator piezoelectric elements were separately in pair connected with $R L C_{\mathrm{P}}$ circuit. The parameters of vibrations are: voltage on the external surfaces of piezoelectric elements and transversal displacement of the middle of plate.

Results of passive damping.

TABLE II

\begin{tabular}{c|c|c|c|c}
\hline \hline Parameter & Unit & Undamped & Damped & Reduction \\
\hline \multirow{2}{*}{ displacement } & {$[\mathrm{mm}]$} & 0.2245 & 0.0602 & 0.1643 \\
& {$[\mathrm{~dB}]$} & 146.7 & 135.6 & 11.1 \\
\hline voltage & {$[\mathrm{V}]$} & 32.2 & 12.2 & 20.0 \\
111 & {$[\mathrm{~dB}]$} & 32.4 & 23.9 & 8.5 \\
\hline voltage & {$[\mathrm{V}]$} & 4.5 & 1.7 & 2.8 \\
222 & {$[\mathrm{~dB}]$} & 15.3 & 7.1 & 8.2
\end{tabular}

In Fig. 4 there is shown the level of voltage amplitude with and without damping and in Fig. 5 there is shown level of amplitude of transversal vibrations in the middle of the plate for the same two cases. The reached values of amplitudes of vibrations are given in Table II.

\section{Simulation of active damping}

The realization of active damping was based on the strategy proposed by Filipek and Wiciak [16]. The detected voltage on the chosen piezoelectric was applied to 


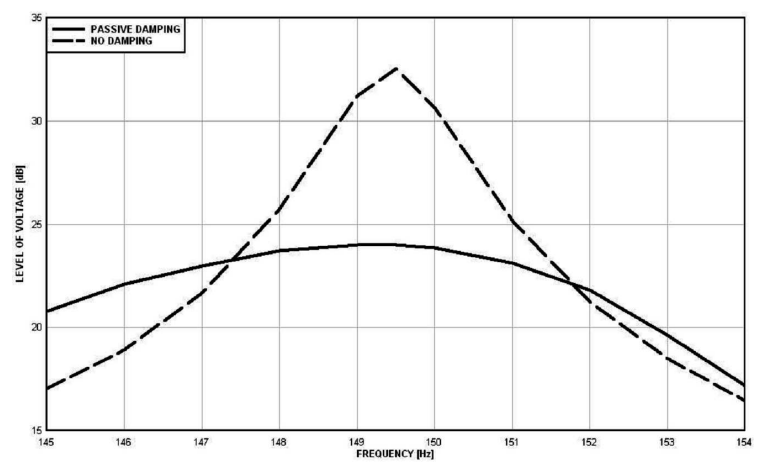

Fig. 4. Results of passive damping for piezoelectric shunt 111, as level of voltage vs. frequency.

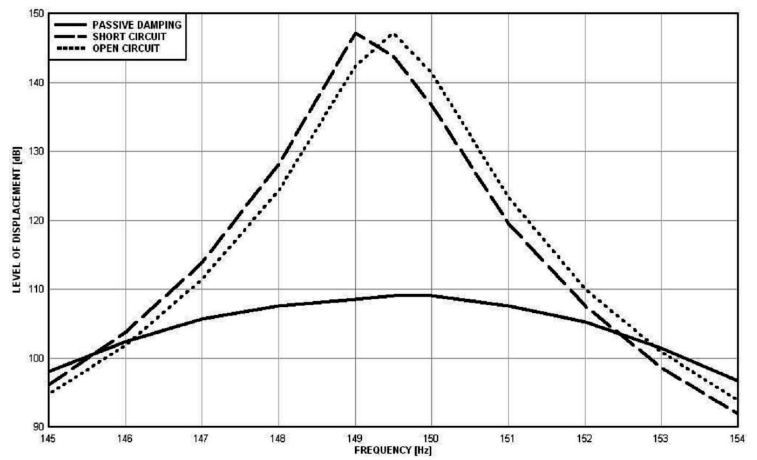

Fig. 5. Results of passive damping in the middle of plate, as level of displacement vs. frequency.

the piezoelectric actuators with the same frequency and suitable phase. The amplitude of voltage was chosen to minimize the phase angle between voltage and excitation. The range between $2 \mathrm{~V}$ and $200 \mathrm{~V}$ was detected, due to possibility of practical realization. The optimal value of damping voltage amplitude was $132 \mathrm{~V}$ (see Figs. 6, 7).

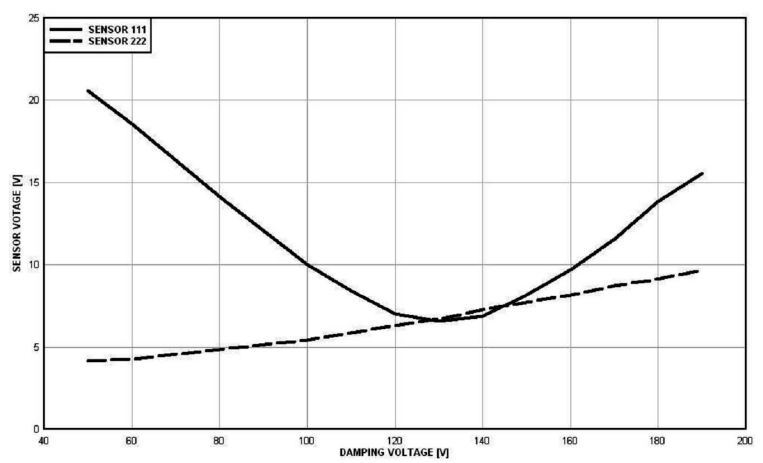

Fig. 6. Choosing of optimal piezoelectric voltage sensor voltage.

Results of simulation are given in Table III. In Fig. 8 there is shown the level of amplitude of transversal vibrations in the middle of the plate with and without damp-

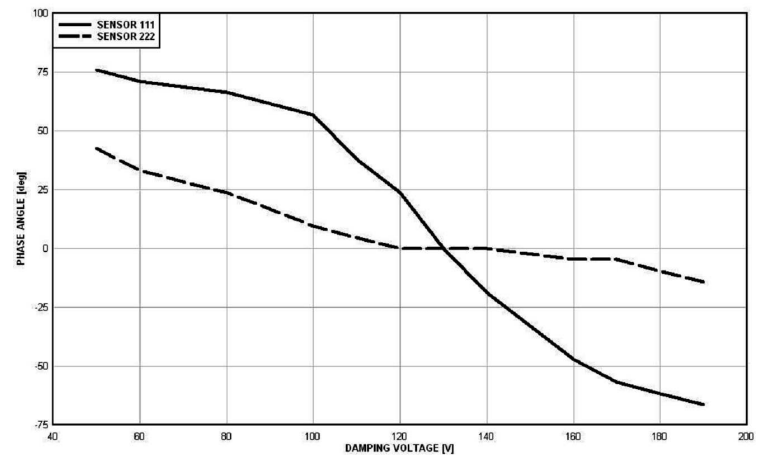

Fig. 7. Choosing of optimal piezoelectric voltage phase angle.

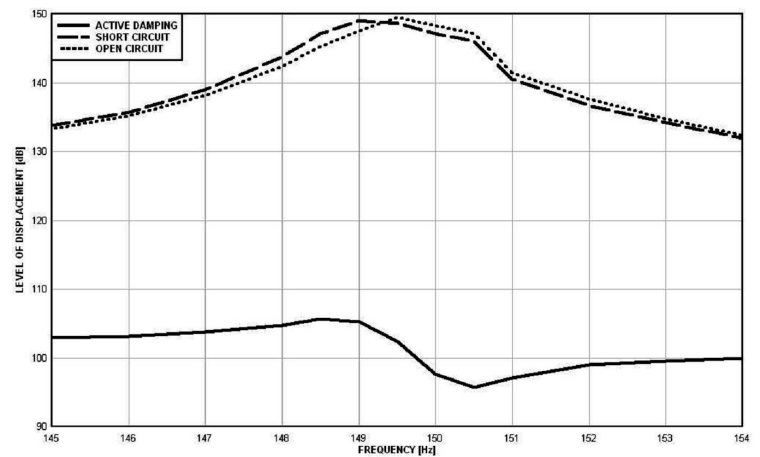

Fig. 8. Results of active damping in the middle of plate, as level of displacement vs. frequency.

ing. However the general effect of vibration reduction is spectacular, in some areas the obtained voltage is a little higher than for undamped structure. It is a local effect, which show needness of choosing the suitable criterion of minimization.

\section{Conclusions}

The aim of analysis was to compare the two attempts for damping of plate vibration by piezoelectric elements: passive and active ones. The simulation was done for the first natural frequency of bending vibrations, thus is connected with the mode shape. The reduction of ex-

Results of active damping.

TABLE III

\begin{tabular}{c|c|c|c|c}
\hline \hline Parameter & Unit & Undamped & Damped & Reduction \\
\hline \multirow{2}{*}{ displacement } & {$[\mathrm{mm}]$} & 0.2245 & 0.0018 & 0.2227 \\
& {$[\mathrm{~dB}]$} & 146.7 & 102.8 & 43.9 \\
\hline \multirow{2}{*}{ voltage } & {$[\mathrm{V}]$} & 32.2 & 6.7 & 25.5 \\
111 & {$[\mathrm{~dB}]$} & 32.4 & 18.7 & 13.7 \\
\hline voltage & {$[\mathrm{V}]$} & 4.5 & 6.9 & -2.4 \\
222 & {$[\mathrm{~dB}]$} & 15.3 & 19.1 & -3.8
\end{tabular}


cited vibrations in the middle of plate (displacement) were $11.1 \mathrm{~dB}$ for passive method and $43.9 \mathrm{~dB}$ for the active one.

The simply form of realization of passive system makes them easy to application for the designed frequency. Unfortunately, the level of reduction is significantly lower than for active attempt. Moreover, the changing of parameter of the circuit, especially changing of piezoelectric capacitance with changing of temperature, makes it much more sensitive in applications. Disadvantages of active system are the extra measuring elements and extra controlled power voltage system.

The level of reduction depends on values of parameters of passive circuit or voltage for the active one. The results depend on configuration of piezoelectric shunts, having in mind the configuration of vibrating plate. It should be noted that in some cases, local increase of vibration is possible.

The obtained values of vibration reduction show possibilities of application of the piezoelectric damping systems in practical application for plates.

\section{References}

[1] S.P. Elliott, P.A. Nelson, Active Control of Vibrations, Academic Press, London 1997.

[2] S.O.R. Moheimani, IEEE Trans. Contr. Syst. Techn. 11, 482 (2003).

[3] S.O.R. Moheimani, A.J. Fleming, Piezoelectric Transducers for Vibration Control and Damping, Springer, London 2006.
[4] A. Brański, S. Szela, Arch. Control Sci. 17, 427 (2007).

[5] A. Brański, S. Szela, Arch. Acoust. 33, 521 (2008).

[6] M.S. Kozień, J. Wiciak, Mol. Quant. Acoust. 26, 183 (2005).

[7] M.S. Kozień, J. Wiciak, Arch. Acoust. 33, 643 (2008).

[8] J. Wiciak, Pol. J. Env. Stud. 13, 125 (2004).

[9] J. Wiciak, Mol. Quant. Acoust. 25, 281 (2004).

[10] J. Wiciak, Arch. Acoust. 31, 503 (2006).

[11] M.S. Kozień, Acoustic Radiation of Plates and Shallow Shells, Monograph 331, Cracow University of Technology, Cracow 2006 (in Polish).

[12] J. Wiciak, Vibration and Structural Acoustic Control - Selected Aspects, AGH - UST, Monograph 175, Cracow 2008.

[13] M.S. Kozień, B. Kołtowski, in: Proc. XII Conf. Vibroacoust. Vibrotechn. and VII Sem. Vibroacoust. Techn. Syst., AGH University of Science and Technology, Cracow 2006, p. 128.

[14] M.S. Kozień, B. Kołtowski, in: Abstr. XV Conf. Biomed. Acoust. Eng., AGH University of Science and Technology, Cracow-Zakopane 2008.

[15] M.S. Kozień, B. Kołtowski, in: Abstr. XV Conf. Biomed. Acoust. Eng., AGH University of Science and Technology, Cracow-Zakopane 2009.

[16] R. Filipek, J. Wiciak, Arch. Mech. Eng. 53, 5 (2006).

[17] N.H. Hagood, A. von Flotow, J. Sound Vibr. 146, 243 (1991). 